\title{
Mineração
}

\section{Análise de sensibilidade na otimização econômica de uma cava}

\section{(Analysis of sensitivity of the pit economic optimization)}

\author{
Belisario Ascarza Flores \\ Engenheiro de Minas, Bolsista da CAPES, Mestrando do Programa de Pós-Graduação em Engenharia Mineral \\ Departamento de Engenharia de Minas, Escola de Minas da Universidade Federal de Ouro Preto \\ E-mail: beliascarza@yahoo.com.br \\ Ivo Eyer Cabral \\ Professor Adjunto do Programa de Pós-Graduação em Engenharia Mineral \\ Departamento de Engenharia de Minas, Escola de Minas da Universidade Federal de Ouro Preto \\ E-mail: cabralmg@uol.com.br
}

\section{Resumo}

Uma das variáveis que torna um projeto de mineração mais vulnerável à instabilidade econômica é a variação dos preços de venda dos minérios. Nesse trabalho, procedeu-se a uma análise de sensibilidade de cavas ótimas em relação à variação do preço de venda de um bem mineral. Foi gerada uma série de contornos de cavas ótimas com diferente valor presente líquido (VPL) e diferentes quantidades de minério e estéril, a partir da aplicação de fatores de desconto sobre um preço de venda de minério tomado como base. Análises desse tipo são úteis para o estabelecimento do planejamento de produção de uma mina. Para esse estudo, foram utilizados dados da mina Morro da Mina da Rio Doce Manganês S.A. e, para a geração das cavas otimizadas, utilizou-se o módulo Pit Optimiser do Gemcom Surpac 6.0.

Palavras-chave: Planejamento, otimização, análises de sensibilidade, Gemcom Surpac 6.0.

\begin{abstract}
One of the variables that makes the economic stability of a mining project more vulnerable is the variation of ore sale prices. In this work, a sensitivity analysis of optimum pits in relation to the variation of the sale price of ore was performed. It generated a set of optimal pits shells with different net present values (NPV) and different amounts of ore and waste, and the application of discount factors of the ore's sale price was taken as the base. Analyses of this type are useful for the establishment of production planning of a mine. For this study, data obtained from the manganese mine of Morro da Mina of Rio Doce Manganês S.A. was used, and the modulate Pit Optimiser of the Gemcom Surpac 6.0 was applied to generate the optimum pits.
\end{abstract}

Keywords: Planning, optimization, analysis of sensibility, Gemcom Surpac 6.0. 


\section{Introdução}

Um problema fundamental no planejamento da mina é determinar o limite da cava final ótimo de uma mina a céu aberto. O limite da cava final ótimo fica definido pelo contorno que é resultado da extração do volume de material que maximiza o benefício (lucro) da mina, satisfazendo os requerimentos operacionais, ambientais e de segurança das paredes da cava. Usualmente esses contornos servem de base para o desenho da cava operacional final.

O desenho ótimo da cava desempenha um papel importante em todas as etapas da vida de uma mina a céu aberto: na etapa do estudo de viabilidade, etapa de operação e etapa final da vida da mina onde o desenho final da cava pode permitir a finalização econômica de um projeto. Em todas as etapas, tem-se a necessidade da supervisão constante da cava ótima, que permita desenvolver o melhor planejamento de longo, médio e curto prazo da mina para a extração eficiente da reserva (Caccetta, L. et alii, 2003).

O problema principal que preocupa as empresas do setor mineral é como definir as porções de minério do depósito que podem ser economicamente mineradas. As técnicas para se avaliarem as reservas econômicas requerem a construção de um modelo de blocos gerado com informação geológica normalmente obtida a partir de sondagem na etapa de exploração. A cada bloco desse modelo se associam informações tais como teor, densidade, tipo litológico, etc. Utilizando essas informações se calcula o valor econômico para cada bloco, que é, quase sempre, o benefício ou lucro que se espera obter com a extração e tratamento do conteúdo mineral presente em cada bloco (Bustillo, R.M. et alii,1997).

A etapa seguinte consiste na definição da geometria final da cava, para a qual se pode utilizar qualquer método de otimização da mesma (algoritmo de Lerchs-Grossmann, Cone Flutuante, etc.). Com base no modelo econômico derivado da quantidade de minério, é gerado um agrupamento de cavas ótimas (nested pits). Essas cavas ótimas são resultantes da aplicação do um algoritmo de otimização repetidas vezes, para diferentes valores líquidos dos blocos, que se obtêm ao fazer variar o preço de venda do bem mineral. Essa seqüência de cavas otimizadas permitiu desenvolver análises de sensibilidade e estudos de viabilidade econômica, que ajudaram a identificar os limites de lavra da cava, ao mesmo tempo em que se maximiza o VPL do projeto.

A configuração da cava final é geralmente definida utilizando o preço mais provável do bem mineral (considerando o mercado). Para preços menores do que esse valor, sucessivamente são geradas cavas menores, que migram em direção às áreas de maior teor e menor razão estéril/minério (Hustrulid, W. et alii, 2006). Esses contornos das cavas podem ser utilizados como guia para a determinação das seqüências da extração de minério e estéril da cava.

\section{Metodologia 2.1 Estudo de caso}

O projeto de cava ótima depende do modelo geológico de blocos do depósito com informações de qualidade (normalmente teores), densidade, tipos litológicos e tamanho dos blocos. Ele é função também de considerações tecnológicas, geotécnicas e econômicas (custos envolvidos na lavra e processamento, preço de venda, recuperação na lavra e no processamento, etc.) e de restrições geométricas e ambientais.

Para a realização desse estudo, foram utilizados dados da mina de manganês a céu aberto Morro da Mina, localizada em Conselheiro Lafaiete (MG), de propriedade da Rio Doce Manganês S.A., empresa pertencente à companhia VALE.

\subsection{Dados utilizados}

\subsubsection{Modelo de blocos}

O modelo de blocos tridimensionais da Mina Morro da Mina contém os seguintes atributos: teor de manganês, teor de ferro, teor de sílica, densidades dos blocos, códigos litológicos do modelo geológico e classificação dos recursos (medido, indicado e inferido).

Além dos atributos já mencionados, para a realização da otimização, foi preciso criar, no modelo de blocos, os seguintes atributos adicionais:

- Tipo de minério: para identificar blocos de minério e estéril. Nesse estudo, foram considerados só os recursos classificados como medidos e indicados.

- Tipo de material: para especificar os parâmetros de custos, já que os custos de lavra mudam dependendo do tipo de material.

- Tipo de maciço: para identificar os tipos de maciços dos setores geotécnicos, já que os ângulos de taludes finais mudam para cada tipo de maciço.

É importante mencionar que, para publicar essa avaliação e manter em reserva dados confidenciais da mina, fezse uma mudança no tamanho dos blocos originais de 7,62 x 2,5 x $10 \mathrm{~m}^{3}$ para $7,62 \times 5 \times 10 \mathrm{~m}^{3}$. Essa reblocagem implicou um incremento do volume de minério, juntamente com uma diminuição dos teores de manganês, ferro e sílica. Os blocos de minério são mostrados na Figura 1.

\subsubsection{Preço do minério}

O custo de produção do minério de manganês não pode ser maior do que US\$ 2.00 por ponto porcentual de manganês, que é igual ao preço US\$ 61.00/t com um teor médio 30,5 \% de manganês. Este é um preço de transferência padrão utilizado pela VALE e é semelhante ao custo de desenvolvimento de uma nova planta de ferro-ligas, considerando a importação de minério de manganês de Gana que chegaria à região com um valor de US\$2.80 por ponto porcentual de manganês igual a US\$ 69.50/t com um teor médio 30,5 \% de manganês. Esse preço pode ser considerado como um preço médio mundial referente aos três últimos anos. 


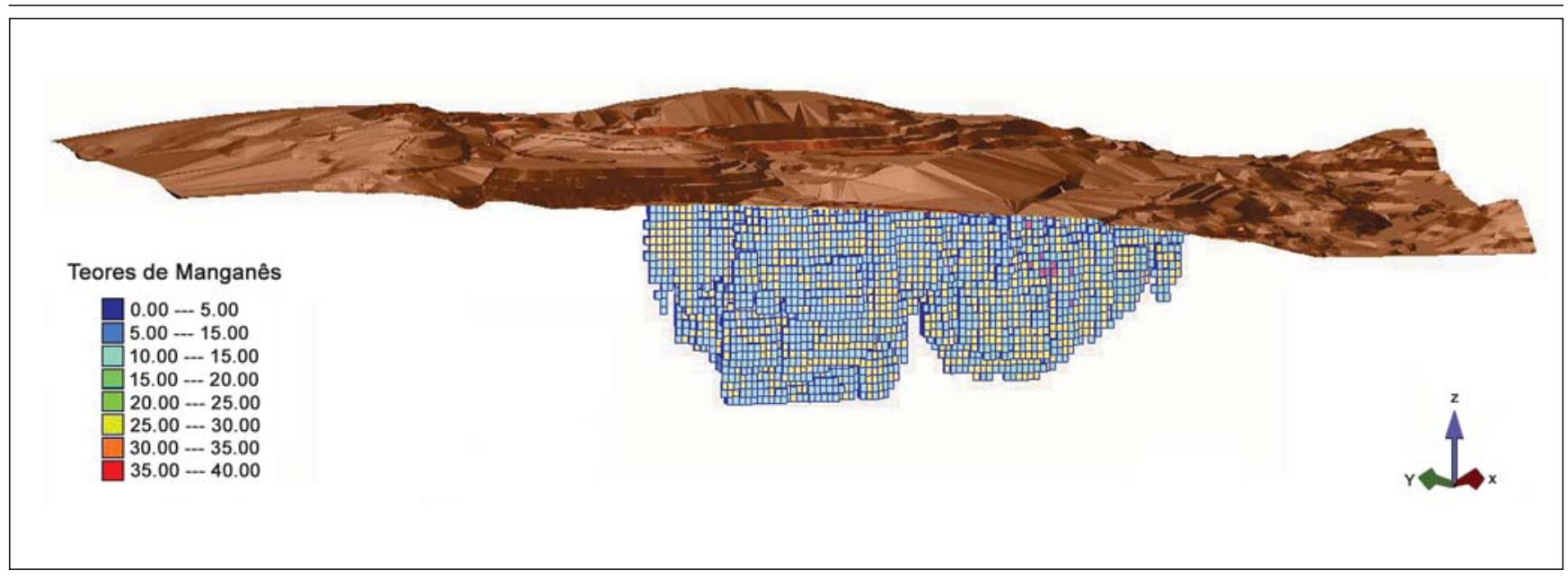

Figura 1 - Blocos de minério de manganês e topografia atual da mina Morro de Mina.

\subsubsection{Parâmetros econômicos}

Nessa avaliação, foram utilizados os custos seguintes (Rio Doce Manganês, 2006):

- Custo de lavra do material minério compacto: US\$ $9.44 / \mathrm{m}^{3}$.

- Custo de lavra do material estéril compacto: US\$ 7.89/m³.

- Custo de lavra do material estéril friável: US\$3.86/m³.

- Custo de processamento: US\$ 4.93/ tROM.

Nessa avaliação, foi feita a distinção do material estéril em friável e compacto, uma vez que os custos de mina associados a esses materiais são diferentes, pois o material friável não demanda desmonte por explosivos.

Além disso, considerou-se um incremento no custo de lavra de $1 \%$ cada vez que a cava aprofunda $10 \mathrm{~m}$, começando no nível 900, para se levar em conta o incremento dos custos de transporte.

\subsubsection{Recuperações de minérios}

Foi considerada uma recuperação média na mina de $70 \%$ e, no processamento, de $85 \%$. Foi utilizado um teor de corte de 20 \% de manganês, ou seja, blocos com teores menores foram considerados como estéril.

\subsubsection{Valor econômico dos blocos}

O valor econômico de cada bloco foi calculado simplesmente pela diferença entre receitas e despesas. As receitas foram calculadas levando-se em conta o preço de venda do minério, o teor de manganês e as recuperações na mina e processamento, enquanto que, para as despesas, foram considerados os custos de lavra e processamento.

\subsubsection{Restrições geotécnicas}

A cava de Morro da Mina foi setorizada em domínios geotécnicos (Figura 2) pela Sergio Brito Consultoria - SBC, de tal forma que cada setor contém três maciços com diferentes ângulos de talude, conforme a Tabela 1.

\subsection{Otimização da cava}

Preparado o modelo de blocos com os diferentes atributos mencionados

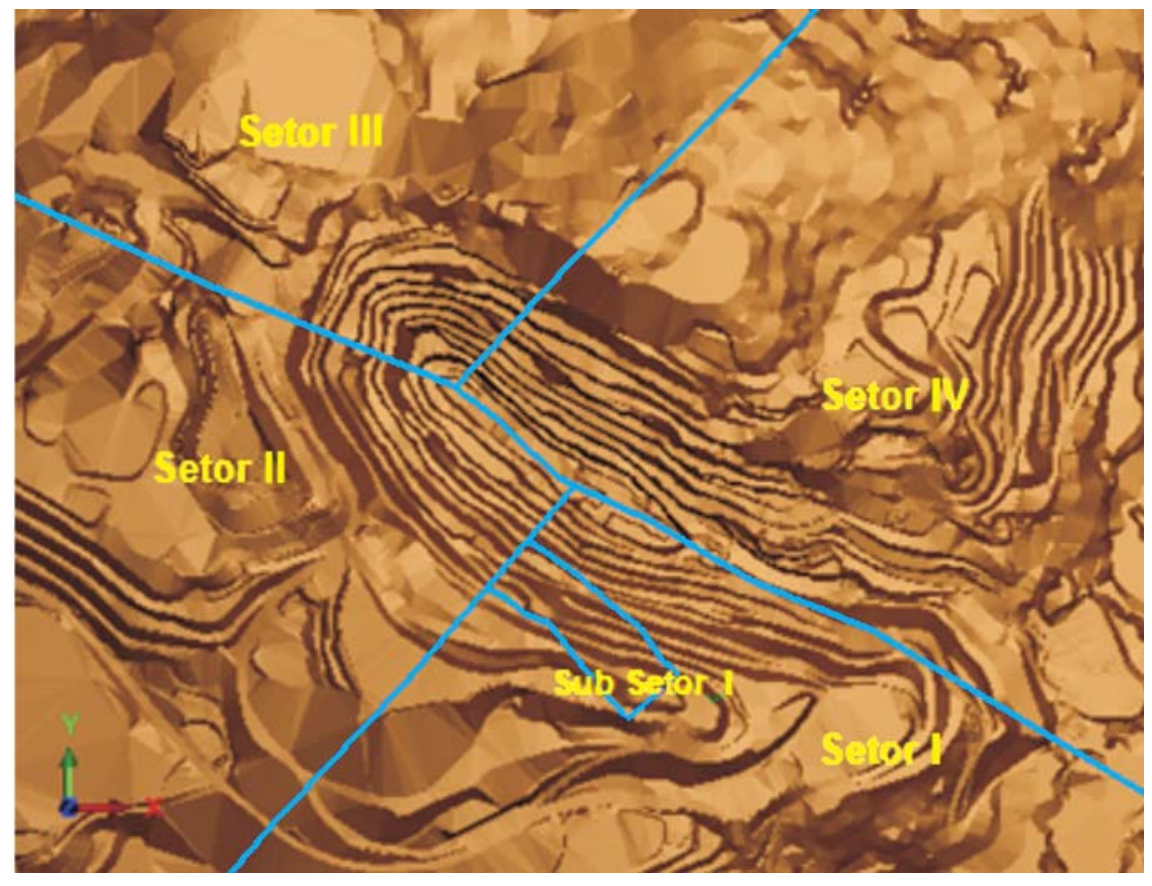

Figura 2 - Setores geotécnicos da mina Morro da Mina segundo SBC. 
Analise de sensibilidade na otimização econômica de uma cava

anteriormente, procedeu-se à otimização da cava para diferentes preços de venda com o módulo Pit Optimiser do sistema computacional Gemcom Surpac.

O Pit Optimiser é uma ferramenta prática e efetiva para realizar a otimização econômica da cava de projetos de mineração a céu aberto, que utiliza os algoritmos matemáticos clássicos, como os de Lerchs-Grossmann e Cone Flutuante, visando a maximizar o valor presente líquido (VPL) do projeto. Esses algoritmos podem ser utilizados separadamente ou em conjunto (Rowdy, B., 2006).

Utilizando o Pit Optimiser, foram aplicados fatores de desconto ao preço de venda do minério para analisar a sensibilidade das cavas ótimas em relação às variações do preço do minério. $\mathrm{O}$ fator de desconto é uma percentagem do preço de venda do minério, que representa de quanto o preço base ou mais provável do minério será diminuído, no intuito de se realizarem análises de sensibilidade à variação do preço do bem mineral que estiver sendo extraído. Para as diferentes percentagens de desconto incorporados na otimização, foram gerados contornos de cavas ótimos (nested pit shells), os quais foram avaliados e comparados.

Os fatores de desconto utilizados e os respectivos preços de venda de manganês, para cada cava, encontram-se na Tabela 2.

\section{Resultados e discussão}

- Variando os fatores de desconto de $0 \%$ ate $50 \%$ (Tabela 2), aplicados ao preço de venda de minério de manganês, foram gerados, sistematicamente, 11 contornos de cavas finais (nested pit shells), cada um com um Valor Presente Líquido (VPL) específico. Para preços menores do que US\$ 2,00/\% Mn, foram geradas sucessivamente cavas menores, que, por sua vez, “migram” em direção às cavas com menor VPL e com menor razão estéril/minério (REM). Os resultados da otimização são mostrados na Tabela 3.

Tabela 1 - Ângulos de talude para cada maciço segundo SBC.

\begin{tabular}{c|c|c|c|c}
\hline \multirow{3}{*}{ Setor } & \multirow{2}{*}{ Maciço } & \multicolumn{2}{|c|}{ Cotas } & Ângulo \\
\cline { 2 - 5 } & & De & Até & Talude \\
\hline \multirow{4}{*}{ I } & A & 830 & 930 & 52 \\
\cline { 2 - 5 } & B & 930 & 940 & 45 \\
\cline { 2 - 5 } & B & 940 & 980 & 45 \\
\cline { 2 - 5 } & C & 940 & 1110 & 26 \\
\cline { 2 - 5 } & C & 980 & 1010 & 26 \\
\hline \multirow{4}{*}{ II } & A & 840 & 960 & 52 \\
\cline { 2 - 5 } & B & 960 & 980 & 42 \\
\cline { 2 - 5 } & C & 980 & 1020 & 26 \\
\hline \multirow{4}{*}{ III } & A & 840 & 945 & 52 \\
\cline { 2 - 5 } & B & 945 & 985 & 42 \\
\cline { 2 - 5 } & C & 985 & 1020 & 26 \\
\hline \multirow{4}{*}{ IV } & A & 810 & 930 & 52 \\
\cline { 2 - 5 } & B & 930 & 950 & 42 \\
\cline { 2 - 5 } & C & 950 & 1030 & 26 \\
\hline
\end{tabular}

- A seqüência das onze cavas ótimas geradas permitiu identificar os limites de lavra da cava, ao mesmo tempo em que se maximizou o Valor Presente Líquido (VPL) do projeto. Sendo assim, foram selecionadas a cava 1, como cava final ótima, e as cavas 3 e 8, como cavas críticas (apresentam incrementos relativamente elevados quanto à quantidade de minério e/ou estéril a ser movimentada, bem como VPL altos) (Figura 3), podendo se optar por qualquer uma delas como cavas finais ante uma eventual queda do preço do minério no mercado.

- Finalmente, foram selecionadas também as cavas ótimas 1, 3 e 8, como guia para estabelecer a seqüência da lavra de minério e estéril durante a vida da mina, já que, entre essas cavas ótimas, existem material e espaço de trabalho suficiente para a lavra eficiente e eficaz do recurso. Do ponto de vista financeiro, a melhor estratégia de lavra começa pela cava 8, após realizada sua lavra completa, prossegue-se para a lavra da cava 3 até sua completa execução e, em se- guida, executa-se a lavra da cava 1. Essa estratégia é a que apresenta melhores resultados, pelo adiamento de custos de remoção de estéril e antecipação de receitas pela lavra com teores de corte decrescentes. Dessa forma, o minério de maior valor é lavrado primeiro, maximizando o VPL. Na Figura 4, são mostradas as imagens das superfícies das cavas críticas no formato DTM (Digital Terrain Model), geradas pelo Pit Optimiser, e, na Figura 5, são mostrados os blocos contidos nas cavas críticas. A solução dessa otimização é apresentada no mesmo modelo de blocos do Surpac.

\section{Comentários finais}

- Os contornos de cavas ótimos (nested pit shells), gerados pelo Pit Optimiser, desempenham um papel importante no planejamento de longo, médio e curto prazo da mina para a extração eficiente da reserva, pois definem as áreas de lavra economicamente viáveis (geometria final da 
Belisario Ascarza Flores et al.

Tabela 2 - Fatores de desconto e preços de venda usados na Otimização.

\begin{tabular}{c|c|c|c|c|c|c|c|c|c|c|c}
\hline Desconto \% & 0 & 5 & 10 & 15 & 20 & 25 & 30 & 35 & 40 & 45 & 50 \\
\hline Preço US\$/\%n & 2,0 & 1,9 & 1,8 & 1,7 & 1,6 & 1,5 & 1,4 & 1,3 & 1,2 & 1,1 & 1,0 \\
\hline Cava & 1 & 2 & 3 & 4 & 5 & 6 & 7 & 8 & 9 & 10 & 11 \\
\hline
\end{tabular}

Tabela 3 - Resultados da Otimização da Mina Morro da Mina.

\begin{tabular}{c|c|c|c|c|c|c|c}
\hline Cava & $\begin{array}{c}\text { Preço } \\
\text { US\$/\%n }\end{array}$ & VPL US\$ & Estéril (t) & Minério (t) & Total (t) & Mn (\%) & $\begin{array}{c}\text { REM } \\
\mathbf{m}^{3} / \mathbf{m}^{\mathbf{3}}\end{array}$ \\
\hline 1 & 2 & 128975696,00 & 56563113,28 & 9569857,03 & 66132970,31 & 30,66 & 7,60 \\
\hline 2 & 1,9 & 109566010,00 & 49790584,87 & 8853379,48 & 58643964,35 & 30,59 & 7,23 \\
\hline 3 & 1,8 & 93423033,00 & 38190626,42 & 7606592,41 & 45797218,83 & 30,53 & 6,48 \\
\hline 4 & 1,7 & 78274842,00 & 35116146,71 & 7192331,30 & 42308478,01 & 30,51 & 6,31 \\
\hline 5 & 1,6 & 64234971,00 & 32756044,48 & 6880958,48 & 39637002,96 & 30,44 & 6,14 \\
\hline 6 & 1,5 & 50812293,00 & 29602764,06 & 6430942,61 & 36033706,67 & 30,37 & 5,93 \\
\hline 7 & 1,4 & 40120278,00 & 26365818,33 & 5992300,74 & 32358119,07 & 30,41 & 5,67 \\
\hline 8 & 1,3 & 28844598,00 & 14677315,85 & 4000902,13 & 18678217,98 & 30,70 & 4,77 \\
\hline 9 & 1,2 & 21375178,00 & 8842038,69 & 2962550,46 & 11804589,15 & 30,66 & 3,87 \\
\hline 10 & 1,1 & 15393332,00 & 7117802,61 & 2563901,40 & 9681704,01 & 30,72 & 3,59 \\
\hline 11 & 1 & 10911715,00 & 2973701,97 & 1628345,23 & 4602047,20 & 30,65 & 2,30 \\
\hline
\end{tabular}

cava) e servem de referência para estabelecer a seqüência em que os recursos devem ser aproveitados dentro dessas áreas.

- O Pit Optimiser fornece a solução já diretamente integrada com o modelo de blocos, eliminando, assim, os problemas e os potenciais erros associados à exportação e importação de informações entre outros programas. Os resultados também são apresentados no formato DTM (superfícies), prontos para gerar seções e realizar o desenho operacional da cava.

- AAnálise de Sensibilidade, em relação às variações do preço de venda do bem mineral, é uma prática necessária em projetos de mineração, de forma a se desenvolverem planos de lavra flexíveis às mudanças do preço do minério, que é uma das variáveis

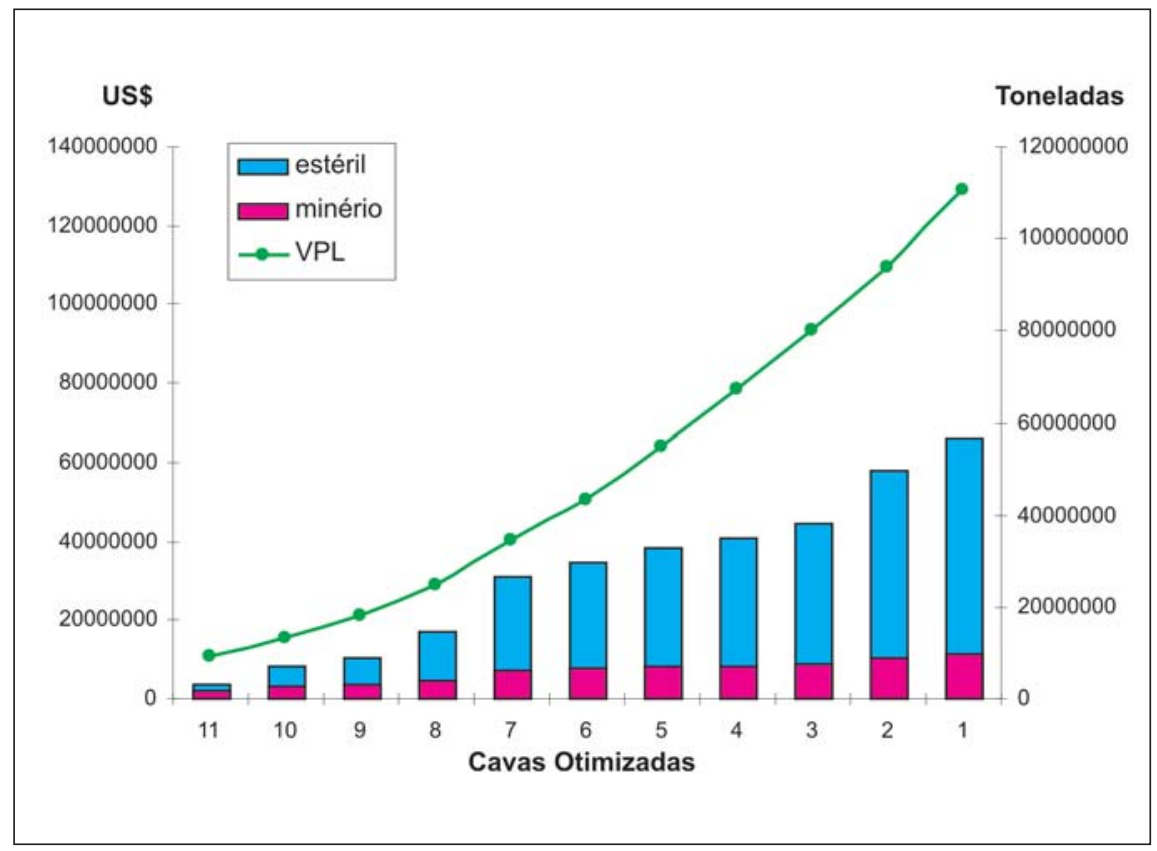

Figura 3 - Comparação entre as onze cavas ótimas geradas pelo Pit Optimiser. 


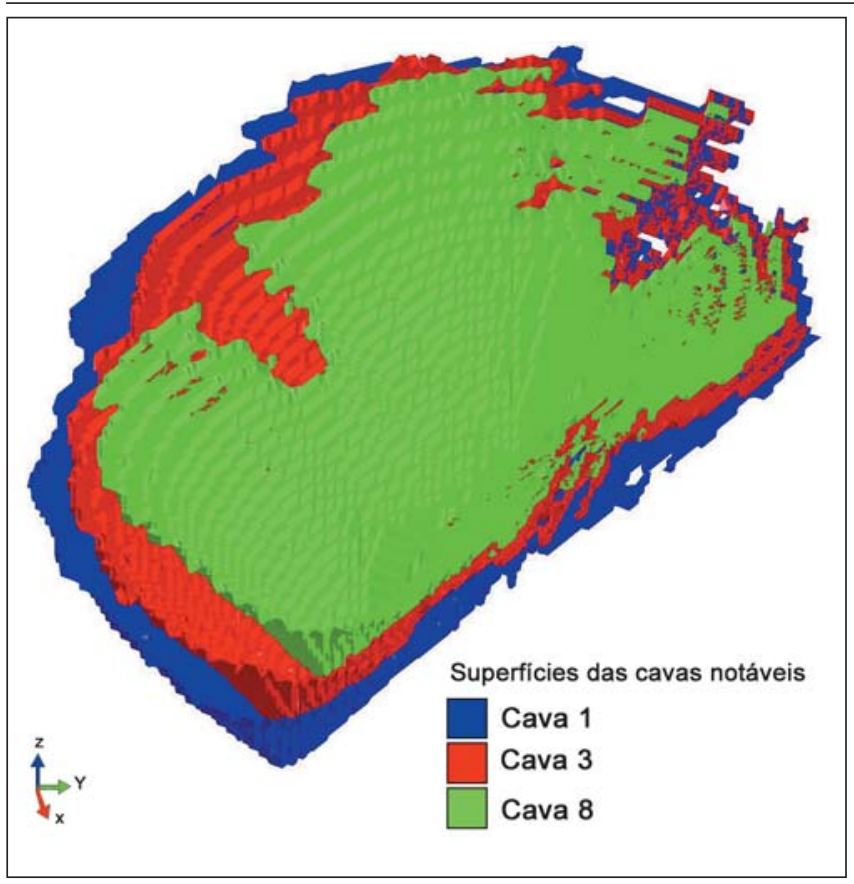

Figura 4 - Superfícies DTM das Cavas Notáveis.

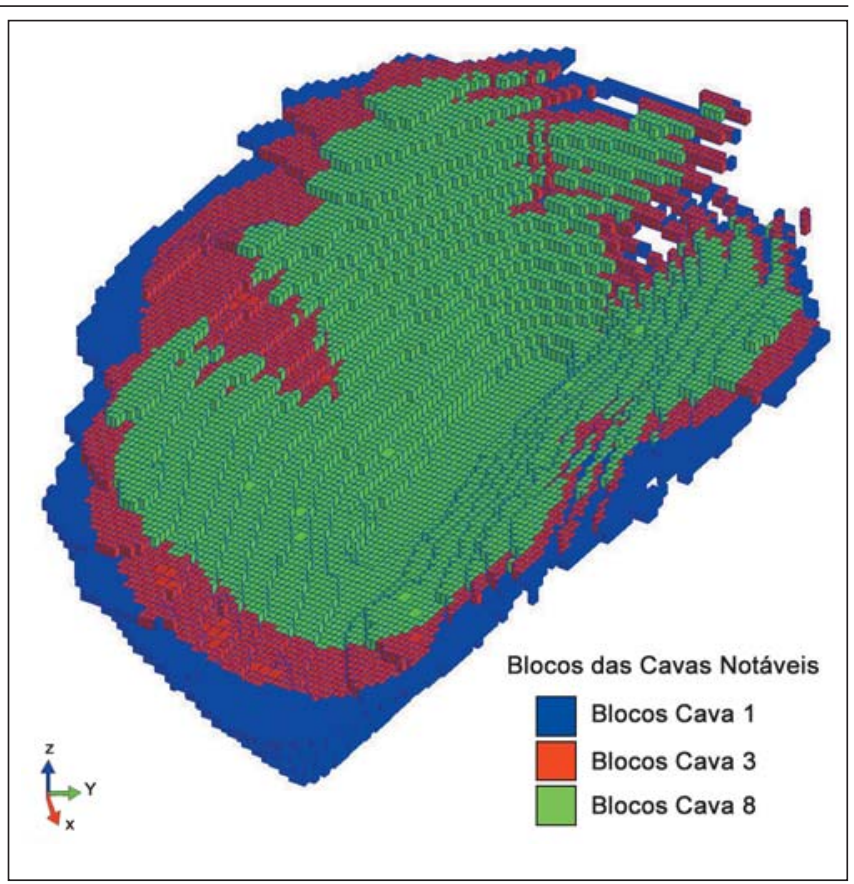

Figura 5 - Blocos contidos em as Cavas Notáveis. externas que torna mais vulnerável à estabilidade econômica de um projeto mineral.

\section{Referências bibliográficas}

BUSTILLO, R.M. et alii. Manual de evaluación y diseño de explotaciones mineras. Madrid: Entorno Grafico, 1997. 353p.
CACCETTA, L. et alii. An application of branch and cut to open pit mine scheduling. Journal of Global Optimization, v.27, n.2-3, p.349-365, 2003.

HUSTRULID, W. et alii. Open pit mine planning and design. (2. ed.). London, UK: Taylor \& Francis, 2006. 494p.

RIO DOCE MANGANÊS. Avaliação de recursos e reservas e plano plurianual de lavra. Conselheiro Lafaiete (MG): Morro da Mina, 2006.

ROWDY, B. Pit optimiser in surpac vision, Perth, Western Australia: Surpac Minex Group, 2006.

\title{
A REM tem novo endereço: Rua Carlos Walter Marinho Campos, 57 Bairro: Vila Itacolomy 35400-000 Ouro Preto - MG
}

\author{
$* * * * * * * * * * * * * *$ \\ www.rem.com.br
}

